\title{
Back protection of canvas paintings
}

\author{
Tim Padfield ${ }^{1 \wedge}$, Nicolas Padfield ${ }^{2}$, Daniel Sang-Hoon Lee ${ }^{3}$, Anne Thøgersen ${ }^{4}$, Astrid Valbjørn Nielsen ${ }^{3}$, \\ Cecil Krarup Andersen ${ }^{3^{*}}$ and Mikkel Scharff ${ }^{3}$
}

\begin{abstract}
In this paper different scenarios for back protection of a canvas painting and their effect on the stability of the relative humidity behind the painting are tested. A painting on canvas, stretched on a wooden frame, was fitted with various styles of back protection and then exposed to a cycle of temperature variation at the back, with the front exposed to a constant room temperature. The painting was also exposed to a constant wall temperature and varying room temperature. The space between the canvas and the back board was fitted with temperature and relative humidity $(\mathrm{RH})$ sensors. The sensors were used to provide the essential single-point data of temperature and $\mathrm{RH}$ at the given locations. For more comprehensive understanding of the rather confined space, further numerical simulation (computational fluid dynamics) was adopted as part of the investigation. The computational fluid dynamics was used to understand the natural convection within the microclimate through the depictions of temperature distribution, as well as the corresponding airflow. The unprotected painting suffered a large $\mathrm{RH}$ variation at its back, because of the varying canvas temperature interacting with the constant room air moisture content. Effective stabilisation of the $\mathrm{RH}$ behind the canvas against temperature variation was provided by a shiny aluminium alloy sheet sealed against the frame. The non-absorbent back board experienced a strong variation in $\mathrm{RH}$, because of humidity buffering of the space by the painting canvas at a different temperature. Either a space or insulation between this back plate and the wall reduced the risk of condensation on the inner surface of the back plate. Insulation will however increase the risk of condensation on the wall surface behind the painting. An absorbent back board de-stabilised the RH at the painting canvas surface by providing a competing humidity buffer at a different temperature. To provide protection against moisture exchange with an unsuitable room RH, extra humidity buffer was placed $3 \mathrm{~mm}$ behind the painting canvas, kept close to the painting temperature by insulation between this buffer and the back board. This stabilised RH at the canvas surface but increased both the temperature and the $\mathrm{RH}$ variation at the back board and thus increased the risk of condensation on the inner surface of the back board. The $\mathrm{RH}$ and the temperature in the narrow spaces between the painting canvas and the wooden stretcher frame were always more nearly constant than in the open canvas area, which suggests an explanation for the widely observed better condition of the areas of canvas paintings which lie close over the support structure. Our conclusion is that a non-absorbent, impermeable back plate gives good RH stability against a changing temperature gradient between wall and canvas painting surface.
\end{abstract}

Keywords: Canvas painting, Relative humidity buffering, Temperature gradient, Back protection

\section{Introduction}

Paintings set against uninsulated outer walls are exposed to varying temperature gradients. Absorbent and

\footnotetext{
*Correspondence: cka@kadk.dk

^Tim Padfield: Deceased

${ }^{3}$ The Royal Danish Academy of Fine Arts, Schools of Architecture Design and Conservation, Phillip de Langes Allé 10, Copenhagen K, Denmark

Full list of author information is available at the end of the article
}

insulating materials within the space enclosed behind the painting affect the moisture content of the painting support in quite a complicated way. This phenomenon is explored through a series of experiments with various arrangements of back protection.

The emphasis is on understanding the micro-environment, using materials and environmental variations which simplify the interpretation. Therefore the materials used in the experiments are not necessarily used by

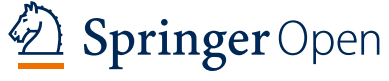

(c) The Author(s) 2020. This article is licensed under a Creative Commons Attribution 4.0 International License, which permits use, sharing adaptation, distribution and reproduction in any medium or format, as long as you give appropriate credit to the original author(s) and the source, provide a link to the Creative Commons licence, and indicate if changes were made. The images or other third party material in this article are included in the article's Creative Commons licence, unless indicated otherwise in a credit line to the material. If material is not included in the article's Creative Commons licence and your intended use is not permitted by statutory regulation or exceeds the permitted use, you will need to obtain permission directly from the copyright holder. To view a copy of this licence, visit http://creativeco mmons.org/licenses/by/4.0/. The Creative Commons Public Domain Dedication waiver (http://creativecommons.org/publicdomain/ zero/1.0/) applies to the data made available in this article, unless otherwise stated in a credit line to the data. 
conservators, but rather represent the simplest possible way of understanding the physical processes. The practical implementation of the physical principles is discussed at the end of the article.

Temperature variation in spaces with a uniform distribution of water vapour, which is the normal situation, is a potent cause of mould growth and humidity induced damage. When such a space contains a moisture buffer material in equilibrium with a moderate relative humidity $(\mathrm{RH})$ and a higher temperature, the $\mathrm{RH}$ at the colder surface can rise very high. The literature, and the advice, on humidity stabilisation of works of art concentrates on the use of hygroscopic materials to slow down the exchange of moisture between an artefact and an ambient atmosphere of unsuitable $\mathrm{RH}$, with the assumption that the temperature will remain uniform over all the participating materials. We have found two articles which quantify the effect on the $\mathrm{RH}$ of a temperature gradient across an enclosed picture. Ligterink and Di Pietro [1] explained the protective effect of stretcher beams close behind the canvas as a result of a disturbance of the temperature gradient influencing the $\mathrm{RH}$ without significant moisture exchange with the stretcher. Padfield et al. [2] measured changes of temperature and $\mathrm{RH}$ within glazed prints set against outer walls of uninsulated houses.

In this article we fill a gap in the conservation literature by exploring the climate within the enclosure behind a painting where moisture leakage to the surroundings is slow, so changes to the RH at the back of the canvas, and consequent changes to its moisture content, are due to temperature change alone. The experiments were made in a strictly controlled environment, to approximate reality, but with imposed simplicity to reveal subtle processes usually masked by the variation of the weather.

\section{Experimental methods}

\section{The experimental arrangement}

The canvas was stretched over a conventional softwood frame (Fig. 1). Staples were used to hold the canvas to the frame. A coat of white acrylic paint was applied to the outside surface. Its uniformity of colour minimised possible temperature variation in the plane of the canvas. An airtight seal for the back plate was made from polyurethane elastomer (Fig. 2).

The painting was held against a vertical painted aluminium plate whose temperature could be varied between 12 and $40{ }^{\circ} \mathrm{C}$. On the right in Fig. 3 is the apparatus for recirculating tempered water through a labyrinth of copper piping behind the plate. The data logger is near the bottom right corner of the plate.

The painting was exposed to a sinusoidally varying temperature of the "wall" at its back, with a nearly constant room temperature at its front. The temperature variation

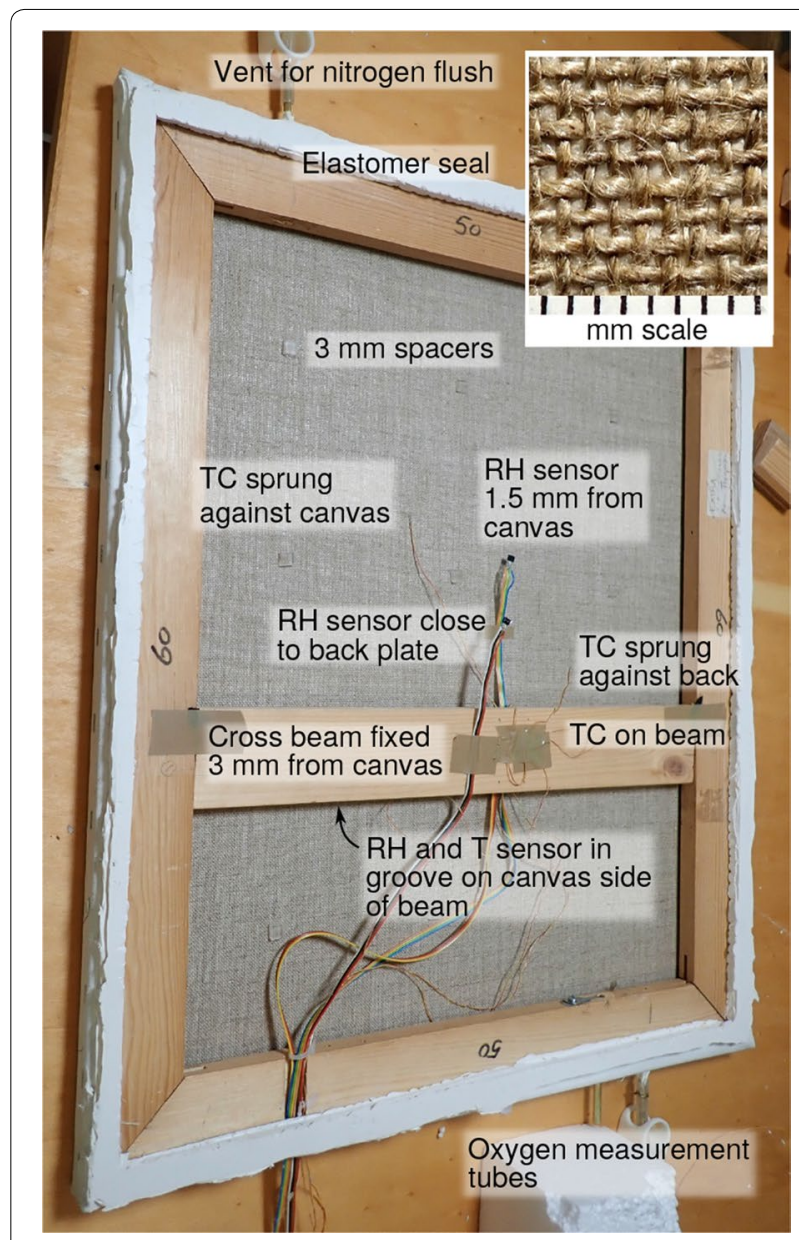

Fig. 1 A back view of the experimental canvas stretched over a wooden frame. The fine thermocouples (TC) which spring against the painting canvas and the back plate are scarcely visible. The RH sensors have built-in temperature measurement. There is a third RH sensor mounted in a shallow groove in the cross beam, facing the canvas. The inset, top right, shows the weave of the linen canvas and the ground layer attached to the far side

for the experiments ranged from 15 to $32{ }^{\circ} \mathrm{C}$ with specific sub-ranges for each experiment. Several cycles were measured for each frame construction, some of a four hour period, to detect rapid effects, some of $24 \mathrm{~h}$ to imitate a real situation. Two typical cycles were extracted for graphical display. In some experiments the painting was set to face the aluminium plate while the back plate was fanned with room air, to simulate a varying room temperature against a constant wall temperature.

\section{The painting and the buffer canvas}

The dimensions of the model painting can be found in Fig. 4. The painting canvas was an open woven linen with factory applied ground. It weighed $447 \mathrm{~g} / \mathrm{m}^{2}$. The loose weave was to limit shrinkage at high $\mathrm{RH}$. The material 


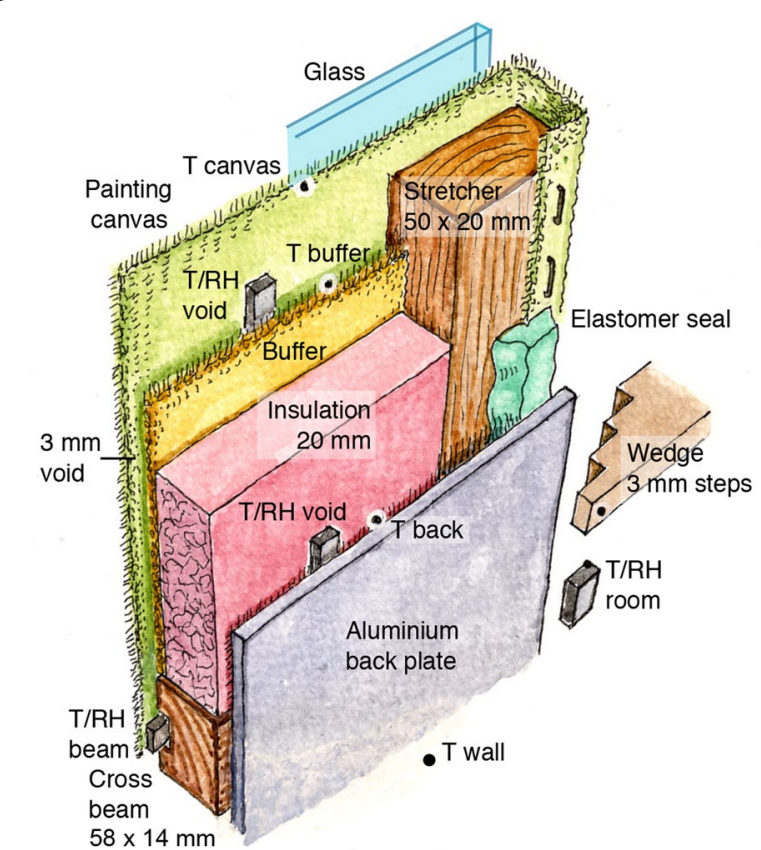

Fig. 2 Positions of all the components and sensors set within and around the painting, viewed from the wall side. The stepped wedge, one of four, is used to hold the assembly at a specified distance from the wall

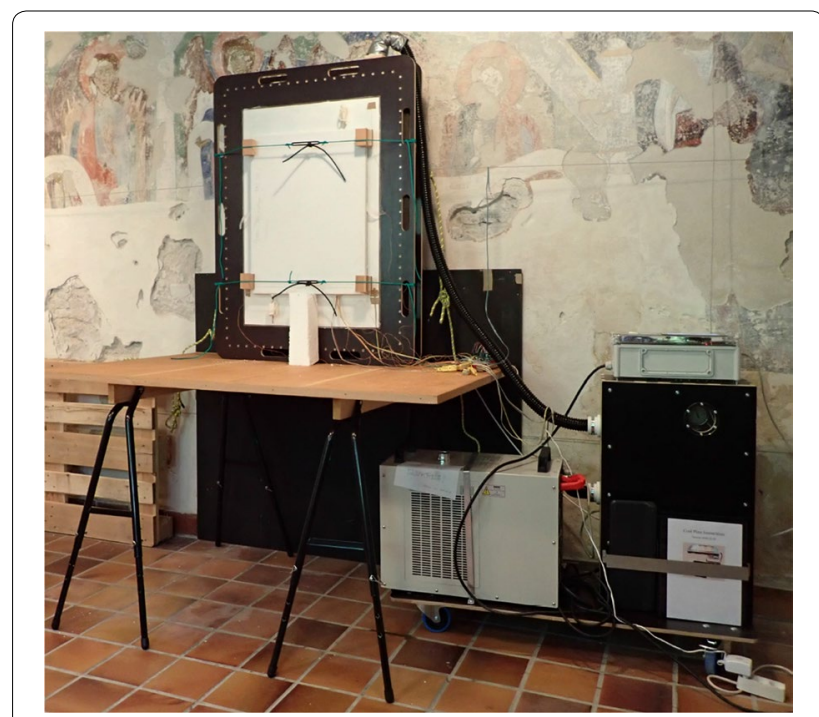

Fig. 3 The experimental painting mounted vertically against a "wall" of painted aluminium which is enclosed flush with a plywood frame

reacted quickly to $\mathrm{RH}$ change, reaching about $80 \%$ of the expected equilibrium moisture content when subjected to an $\mathrm{RH}$ cycle of four hours in a dynamic vapour sorption apparatus (Surface Measurement Systems Ltd UK).
The buffer canvas was a very densely woven cotton fabric, $632 \mathrm{~g} / \mathrm{m}^{2}$. It only came $60 \%$ towards equilibrium, even when exposed on both sides in the sorption apparatus. Because of the difference in weight per unit area, the buffer canvas had more exchangeable water available within the painting assembly. In Fig. 11 the buffer canvas dominates the $\mathrm{RH}$ competition between the two surfaces at different temperatures.

\section{Sensor calibration}

The RH sensors are Honeywell HIH series 8120. They were calibrated over two saturated salt solutions: Sodium chloride at $76 \%$ and magnesium chloride at $33 \%$. The tests were made at three temperatures covering the span of the experimental cycles. The claimed accuracy is $\pm 2 \%$. Three of the four were within $1 \%$ of each other throughout the tests, the fourth, used to measure the room $\mathrm{RH}$, was about $2 \%$ low. The sensors have built in signal processing and cannot be adjusted. However, inconsistencies were very small compared to the $\mathrm{RH}$ values discussed in this article, so no corrections were applied to the graphical results.

The temperature sensors were calibrated against each other through the temperature range, since three different sensor technologies were used in close proximity: type K thermocouples, Platinum $100 \mathrm{ohm}$ resistance sensors and an unidentified type in the Honeywell sensors. The Honeywell sensors proved to be seriously non linear, with kinks in the temperature response, reproducible but different in the four sensors. Only a continuous ramp in temperature revealed the deviations from a linear response. This was a surprising defect in a sensor which is used in many industrial products. We took the average of the thermocouples, and the Pt100 sensors, as the true values and adjusted the raw data to concordance among all the sensors. Even a $0.3^{\circ}$ anomaly in the temperature record produces strange artefacts on the graphs, because the calculated surface $\mathrm{RH}$ depends on two temperature sensors being equally responsive.

\section{The temperature controller}

The 'wall' is an aluminium plate, A1 size $(594 \times 841$ $\mathrm{mm}), 5 \mathrm{~mm}$ thick, grooved at the back to hold an array of copper pipe, $5 \mathrm{~mm}$ internal diameter. Tempered water is pumped through the pipe. The water temperature is adjusted by recirculating it through an electric heater $(600 \mathrm{~W})$ or a heat exchanger connected to an industrial cooler $(680 \mathrm{~W})$ held at $7{ }^{\circ} \mathrm{C}$. The recirculation path is controlled by magnetic valves energised by solid state relays which in turn are controlled by a Raspberry Pi micro-computer running a Python script. The plate temperature is measured by duplicate four wire platinum $100 \mathrm{ohm}$ sensors. A PID controller in the script ensures 
smooth temperature variation. Remote control of the temperature cycle is via a web page. The apparatus and program code is open source. It is described by Padfield and Padfield [3].

Unlike a real wall, this device imposed the programmed temperature on the back plate, regardless of the construction of each experiment. A real wall would interact with the heat flow through the entire arrangement, having some thermal resistance and capacity.

\section{Data logger}

The data logger is also an open source project, based on a Raspberry Pi micro-computer and scripted in Python. The sensors are generic type $\mathrm{K}$ thermocouples, Platinum $100 \mathrm{ohm}$ resistance sensors and Honeywell $\mathrm{HIH}$ 8120 combined humidity and temperature sensors. The signal processing for the thermocouples is by Adafruit MAX31856 boards, and for the Pt100 sensors by Adafruit MAX31865 boards. The Honeywell sensors have built in signal processing and send a digital signal through the I2C protocol.

The Raspberry Pi uses a web server to display a control page which provides a choice of the sensors to log, the measurement interval, and download of accumulated data. This is accessible over the internet and allows remote control of the logging.

\section{Air exchange measurement}

We measured the air exchange rate with a moisture independent method. The painting assembly was flushed with nitrogen to displace most of the air, then the returning oxygen was measured with an optical method based on the quenching of fluorescence of a dye in the presence of oxygen. The air exchange rate was $0.4 / \mathrm{h}$ (Fig. 5).

The measuring instrument was a PreSens detector (PreSens Precision Sensing GmbH, Am BioPark 11, 93053 Regensburg, Germany) which sends a short pulse of bluegreen light through an optical fibre cable towards the sensitive dye which is held against an airtight acrylic window at the end of a brass tube sealed through the painting frame.

\section{Air circulation simulations}

The computational model was constructed with the air volumes and the main structural elements: canvas, wooden stretcher, elastic seal (Sikaflex), and the aluminum back plate. The physical properties used for these elements are given in Table 1.

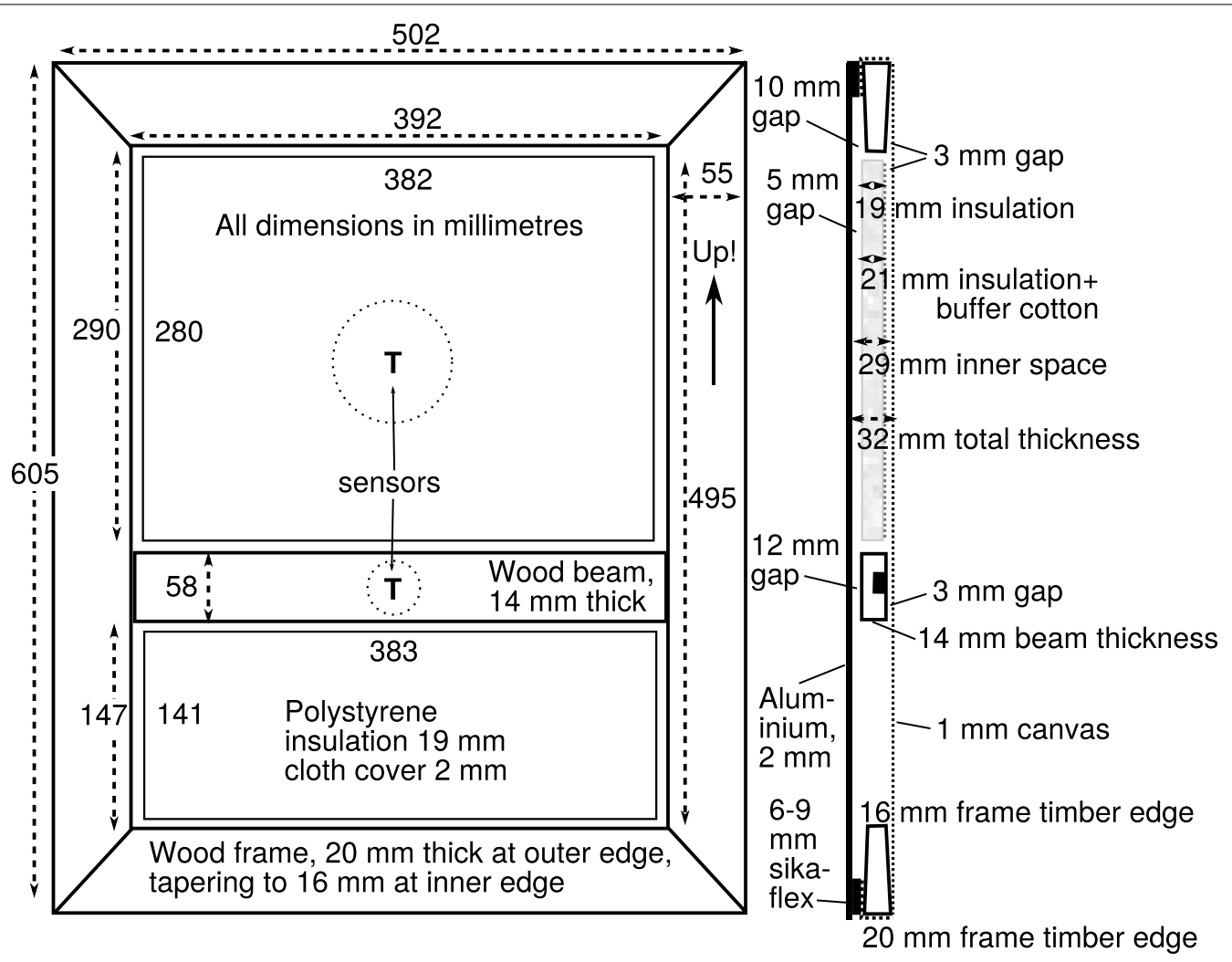

Fig. 4 Dimensions of the painting assembly 


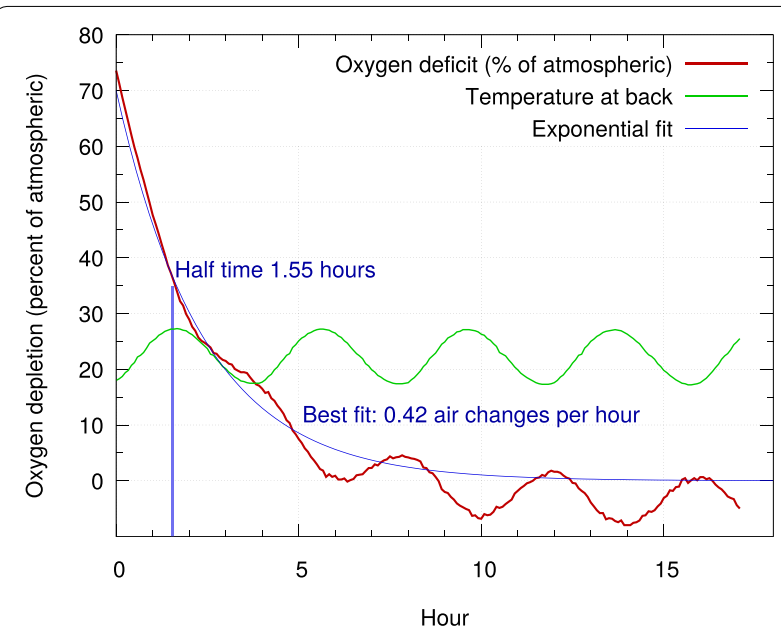

Fig. 5 The air leakage rate, with a fitted curve showing the half time to equilibrium. The oscillation in the oxygen measurement is due to the large temperature dependence of the fluorescence quenching

Table 1 Properties of the solid elements

\begin{tabular}{llll}
\hline Material & Density & $\begin{array}{l}\text { Thermal } \\
\text { conductivity (W/ } \\
\text { mK) }\end{array}$ & $\begin{array}{l}\text { Specific } \\
\text { heat }(\mathbf{J} / \\
\mathbf{k g} / \mathbf{K})\end{array}$ \\
\hline Aluminum & $2719 \mathrm{~kg} / \mathrm{m}^{3}$ & 202.4 & 871 \\
Sikaflex $11 \mathrm{~F}$ & $1200 \mathrm{~kg} / \mathrm{m}^{3}$ & 0.025 & 1800 \\
Canvas & $0.632 \mathrm{~kg} / \mathrm{m}^{2}$ & 0.045 & 1340 \\
Spruce & $450 \mathrm{~kg} / \mathrm{m}^{3}$ & 0.18 & 2300 \\
\hline
\end{tabular}

The simulation was run in ANSYS $^{\circledR}$ Fluent ${ }^{\circledR}$ academic version 19.0 with coupled solver. The thermal boundary conditions were given as constant temperatures at $29.5^{\circ} \mathrm{C}$ and $25.7^{\circ} \mathrm{C}$ to the painting canvas and the backplate respectively. The minimum element size was $1 \mathrm{~mm}$, and a number of models with different inflation layers off the canvas and back-plate surfaces were computed to find the appropriate total thickness which can capture all the laminar flow near the walls. The SST k-omega turbulence model was used with low-Re correction.

\section{Measurement of $\mathrm{RH}$ at a surface}

The relative humidity is the quantity given the most significance in this article. It is the fundamental expression for the potential for water vapour to enter into chemical reactions, cause dimensional change and facilitate biological processes. It is identical to the chemists' concept of water activity, which is defined as the ratio of the actual partial pressure of water vapour in space to the partial vapour pressure over a pure water surface at the same temperature. From this value one can derive quantitatively the change of mechanical properties which cause deterioration of paint layers on canvas, and the risk of fungal growth on the canvas and other parts of the painting assembly.

Within the space between the painting and the back plate, the concentration of water molecules by mass, expressed as a ratio to the mass of dry air, is the quantity which tends towards a uniform value over the entire space, even in a temperature gradient. This is called the mixing ratio (MR) and is displayed on the lower portion of the graphs.

To interpret the processes at work one has to switch back and forth between MR and RH $[4,5]$. The first to describe the migration of water molecules in space, the second to describe migration of water molecules through the material to air interface, which is the buffering process.

It is difficult to be sure of the $\mathrm{RH}$ at a surface, particularly if that surface is moisture reactive. Even miniature RH sensors are bulky, $5 \times 4 \times 2 \mathrm{~mm}$, and obstruct the movement of heat and moisture at the point where they measure.

In these experiments we partially compensated for this practical difficulty by measuring both temperature and relative humidity at a point about $1.5 \mathrm{~mm}$ away from the surface, while also measuring the surface temperature nearby with a thin thermocouple, which hardly interfered with the flux of moisture and heat at the surface.

We then estimated the expected $\mathrm{RH}$ at the surface by dividing the mixing ratio of the air measured at the $\mathrm{RH}$ sensor by the mixing ratio of vapour-saturated air at the surface temperature.

This calculation assumes that there is no significant vapour flux through the surface into the boundary layer. In the experiments described below, this was always true for the aluminium surface of the backing plate. At the canvas surface our RH extrapolation would only be approximate if there were significant moisture exchange between air and canvas.

The magnitude of the difference between the surface $\mathrm{RH}$ and the $\mathrm{RH}$ at a millimetre or two from the surface is significant in interpreting the experimental results. In the graphs, the calculated surface value and the measured value at the $\mathrm{RH}$ sensor are linked by shading.

\section{Results}

The environment of the unprotected painting

All the graphs in this article have the same pattern, with RH curves clustered at the top, temperatures in the middle (with scale on the right side) and mixing ratios in a band at the bottom of the graph. A thumbnail of the structure is shown at the bottom right. Two RH curves are given, the measured value close to the surface of the 
canvas and the value calculated from the surface temperature of the canvas. The two curves are linked by a coloured fill, which is pink for the canvas and, in all the other graphs, blue for the RH close to the back plate.

The graph in Fig. 6 imitates the normal situation of a painting with an unprotected back and ample circulation of room air behind it. In an art gallery this is usually because the top of the painting is tilted away from the wall, but in our experiment we made a uniform $10 \mathrm{~mm}$ gap between frame and wall.

The canvas temperature was approximately half way between ambient and the wall temperature. The vapour concentration at the canvas surface was the same as that in the room, as shown by the nearly identical and flat mixing ratio curves for the room and for the canvas. The $\mathrm{RH}$ varies strongly in opposite phase to the canvas temperature.

The $\mathrm{RH}$ between the canvas and the wooden cross beam was much more stable. The mixing ratio at this sensor deviated from the room value. This indicated vapour exchange with the wood, and with the adjacent canvas, in this poorly ventilated space.

\section{Adding an impermeable back plate}

An impermeable, moisture inert plate of aluminium was fastened to the back of the frame, but still separated from the wall by $10 \mathrm{~mm}$. This gave a completely different microclimate within the sealed enclosure (Fig. 7). There was a nearly constant RH behind the canvas and the temperature cycle was reduced. The RH stability comes from humidity buffering by the painting's canvas, as revealed by the varying mixing ratio, indicating repeating evaporation and absorption of vapour into the confined space. One might object that the infrared reflectivity of the aluminium plate is a factor, but this is only the case when there is a gap between back plate and wall. As can be seen in Fig. 17, the difference in temperature span between "10 mm gap, backed" and "external insulation" is only about 1 degree $\mathrm{K}$ (about 6 degrees $\mathrm{K}$ and about 5 degrees $\mathrm{K}$ respectively), so there is a difference but it is not the significant effect for this experiment.

In this experiment new canvas was used. Degraded canvas, different grounding etc. may have slightly different sorption properties. The data used for sorption calculations is based on a study by Gregers-Høegh et al. [6] The calculations can be found at [7]. The RH close to the cross beam was still very stable. However, the RH at the back plate surface varied strongly over the temperature cycle.

\section{Humidity variation through a temperature gradient}

The varying $\mathrm{RH}$ at the moisture-inert metal back plate can be explained by reference to two well established diagrams, the psychrometric chart and the sorption isotherms of cellulose [8].

The starting point for the graph in Fig. 7 is a uniform environment throughout the assembly at $26{ }^{\circ} \mathrm{C}$ and $60 \%$ $\mathrm{RH}$. When the temperature at the canvas surface declines to $24{ }^{\circ} \mathrm{C}$ at the low point of the temperature cycle, the $\mathrm{RH}$ in equilibrium with the canvas surface falls only about $1 \%$, as defined by interpolation on the graph of sorption isotherms in Fig. 8. So the system moves on the psychrometric chart diagonally down and to the left, following close to the curve for $60 \% \mathrm{RH}$ to the point marked 'canvas.' This corresponds to a lower mixing ratio.

The mixing ratio does not vary with temperature change. A falling temperature will increase the density of the mixture but will not change the ratio between water molecules and air molecules. A changing mixing ratio indicates that vapour is entering or leaving the air through humidity buffering by materials. Also, its variation in space indicates the degree of mixing of the air within the enclosure. In this context, one can regard air as entraining water molecules and helping to distribute them evenly throughout the space. There is no interaction between water vapour and air other than random elastic collisions; one should not regard air as a solvent for water vapour, only as a transport medium.

As the air close to the canvas disperses out into the space behind it, the mixing ratio does not change, because the canvas, which could potentially be a source of water, is in equilibrium with the RH at its surface. When this air reaches the surface of the back plate it is at a point on the diagram which is horizontally at the same level as the 'canvas' point, because the mixing ratio has not changed, but it is at a lower temperature. This point intercepts the curve for $72 \% \mathrm{RH}$.

The mixing ratio alone does not govern the moisture sorption of the materials with which the air is in contact, but in combination with temperature it determines $\mathrm{RH}$. The potency of water vapour for chemical reaction and sorption into solid materials is expressed by the relative humidity. One has to switch focus between mixing ratio, as one possible cause of vapour movement in space, and vapour potential, $\mathrm{RH}$, as a cause of change to artefacts.

In a confined space subjected to a sudden temperature change the exchange of vapour between solid and air is negligible. In this particular picture enclosure of 0.006 cubic metres, a five degree temperature change around $25^{\circ} \mathrm{C}$ will change the water content of the painting canvas by $0.01 \%$ as it maintains a constant $\mathrm{RH}$ in the enclosure. Contrast this modest disturbance with the situation of the unprotected painting, exposed to a varying temperature and the constant mixing ratio of the room air, as in Fig. 6. It seems from the sorption data [7] that the painting canvas will exchange much more water, $1.8 \%$, because 


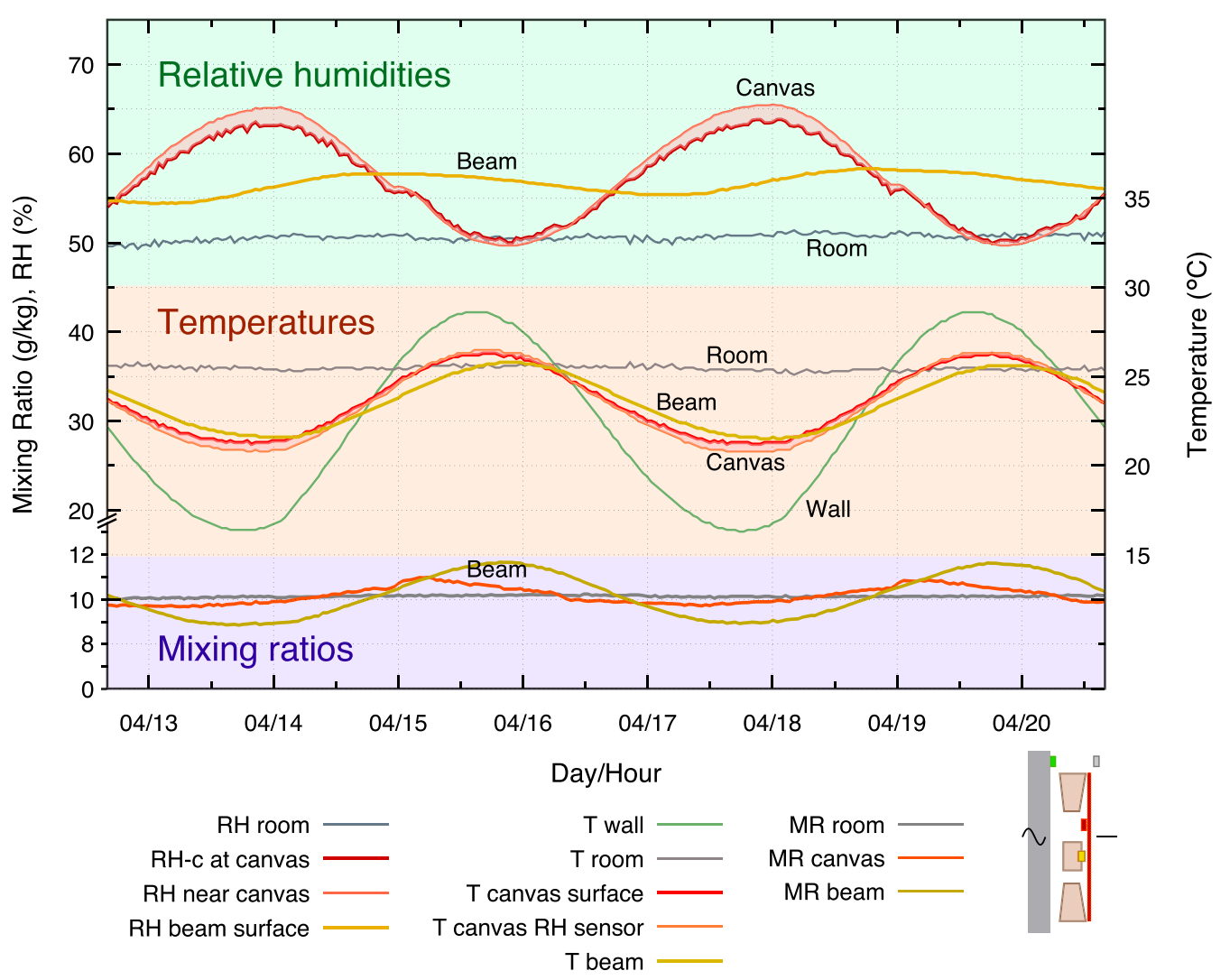

Fig. 6 A 4 h cycle of wall temperature, with an average value below ambient. The painting, without back protection, was mounted with a $10 \mathrm{~mm}$ gap between the frame and the wall. The difference between the RH measured at the sensor $1.5 \mathrm{~mm}$ from the back of the canvas and the RH calculated at the nearby surface temperature is shown by a tinted band. The calculated value is named $\mathrm{RH}-\mathrm{c}$ in the key. The sensor temperature and the canvas surface temperature are also linked by a tinted band. The $\mathrm{RH}$ in the room was the same for all experiments and is therefore not included in other figures with stable room temperature

its surface RH will change substantially, while the mixing ratio will not change (this is a simplified explanation; the situation is complex and should be investigated in future work), being held constant by flushing with room air. Good stability of RH is achieved by very little water exchange by the canvas within a small enclosed volume.

Evidently, a tight enclosure around the painting allows it to control its canvas surface $\mathrm{RH}$ with hardly any moisture exchange. It is the surface $\mathrm{RH}$ which matters; how it is achieved is irrelevant. The addition of an impermeable, non-absorbent back plate is beneficial to a painting on canvas.

\section{Modelling the air flow within the enclosure}

Figure 9 summarises results from computational fluid dynamic (CFD) calculations to support sensor measurements which indicated rapid air mixing within the enclosed space, except in the narrow channel between the painting canvas and the wooden cross beam.
With a temperature difference between back plate and the painting canvas of four degrees, the modelling shows vigorous convective circulation within the vertical space, with a central zone of slow mixing between the rising and falling air streams. It also shows the steeper temperature gradient close to the surfaces with a flatter gradient in the middle. This emphasises both the difficulty of knowing exactly the $\mathrm{RH}$ at the surfaces and the importance of realising how rapidly the $\mathrm{RH}$ changes as one approaches in millimetre detail a surface at a different temperature to that measured in the room.

The left column in Fig. 9 shows the situation in the clear void, with vigorous vertical air movement but with mixing horizontally across the section. Movement in and out of the plane of the section is not displayed. The horizontal movement shown on the graph below the arrows image seems to be very slow, only a hundredth of the vertical speed, but this is misleading because the speed is the net residual velocity of many molecules in the horizontal direction, while the vertical movement is of molecules 


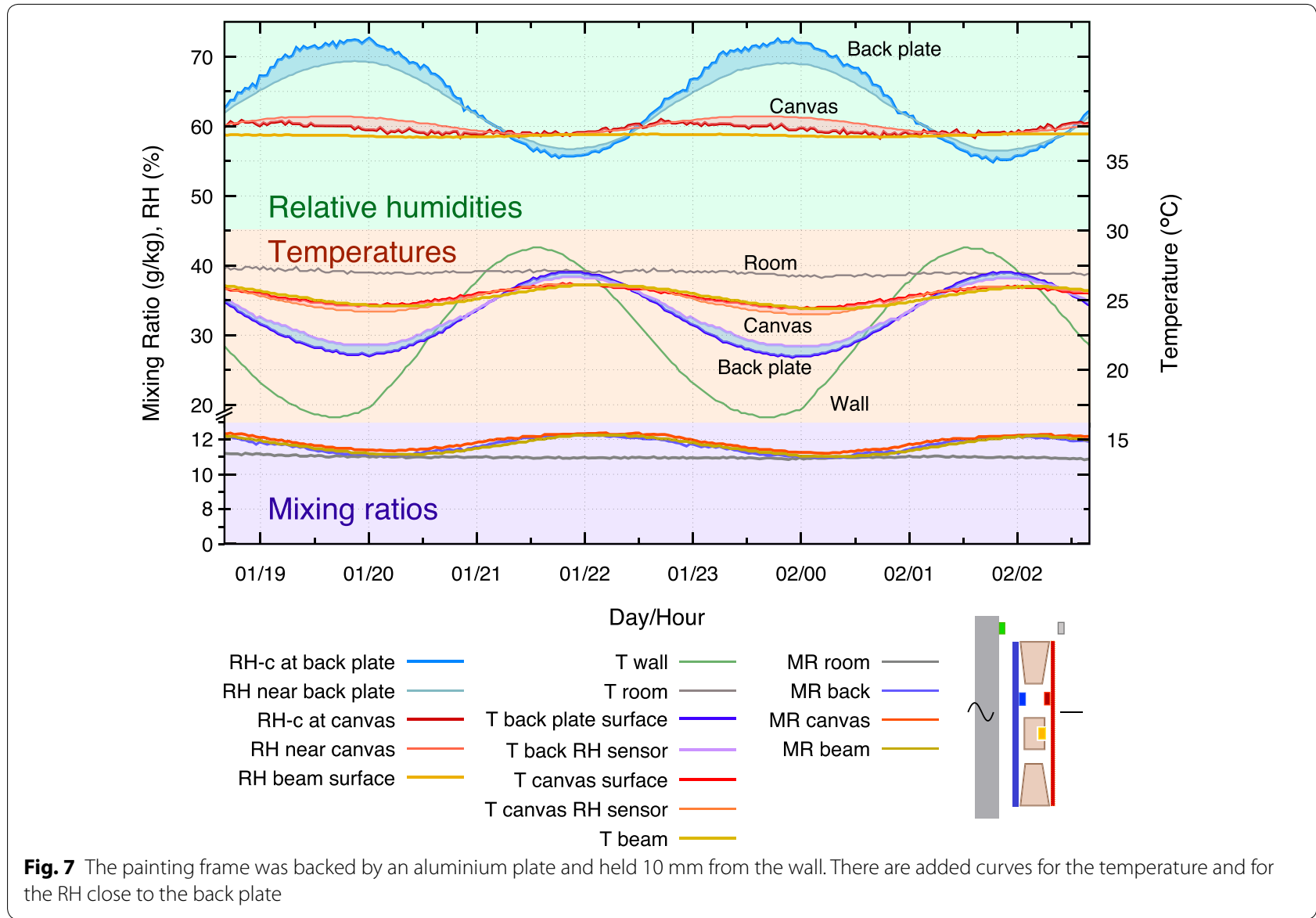

streaming mostly in the same direction as a relatively uniform mob.

The centre column of Fig. 9 shows the effect of the beam. It considerably diminishes the flow on both sides, causing air to circulate mostly in two separate cells above and below the beam. The air flow is one way and sluggish in the $3 \mathrm{~mm}$ gap between beam and canvas, just one sixth of the unimpeded flow in the $29 \mathrm{~mm}$ space between canvas and back plate.

The blocking action of the beam is illustrated in a different way in the column to the right. This shows the stream line of the airflow, which can be used to approximate the possible flow paths of a single particle released within the air volume. It spends a lot of time trapped, slow moving, in a vortex just above the cross beam.

The simulation shows that the stream line of air flow is an elliptical circulation with laminar flow parallel to the two vertical surfaces. It gives no information on the rate of release and absorption of water molecules through the canvas surface.

\section{Insulation between wall and back plate}

The large amplitude of the $\mathrm{RH}$ variation at the back plate shown in Fig. 7 means that if the wall is very cold, there is a possibility of condensation on the inside surface of the back plate. The water can then run down and collect at the bottom of the frame, causing damage to the lower edge of the painting.

The $10 \mathrm{~mm}$ gap between painting and wall is therefore important because it reduces the temperature swing at the back plate. It also allows room air to warm the wall surface where air circulation is restricted by the proximity of the painting and thus inhibit condensation on the wall surface.

When the back plate was set directly against the wall, its $\mathrm{RH}$ exceeded $80 \%$ when the wall temperature reached $16{ }^{\circ} \mathrm{C}$. For this reason, fitting a back protection should be combined with thermal separation from the wall, by a space or by insulation.

Protection against condensation on the interior of the back plate can be provided by putting thermal insulation 

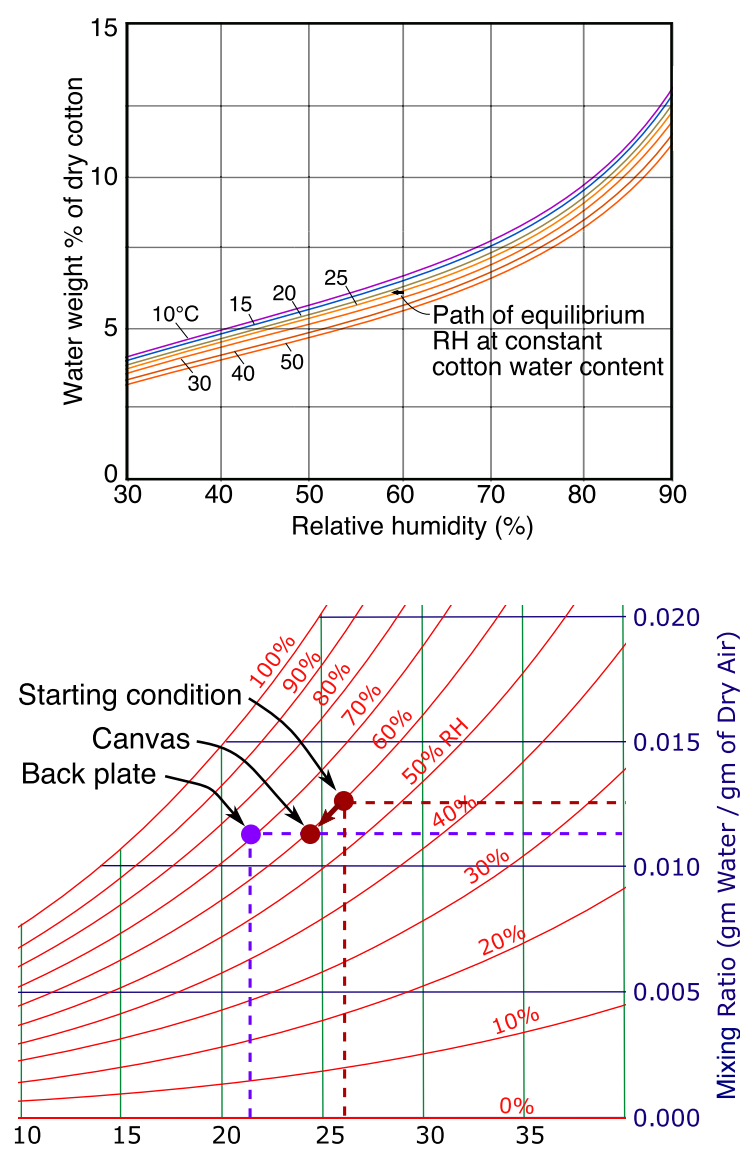

Fig. 8 A simplified psychrometric chart (lower) and part of the sorption curves for cotton, redrawn after Urquhart and Williams [8]

outside the enclosure, between the wall and the aluminium back plate (Fig. 10) acknowledging that this would change the reflective property of the aluminum. The reflective properties, however, are only relevant when there is a gap between the wall and the back plate, which is not the case in this situation. In this case the back plate is placed directly against the wall.

The $\mathrm{RH}$ variation with external insulation of the back protected painting was quite moderate, because the temperature variation at the back of the frame was half of that when the back plate touched the wall. However, the point of condensation danger was shifted to the wall surface behind the insulation, which was now much colder than the exposed wall. This is a particular danger in humidified exhibition rooms in cool climates.

Many conservators use insulating back plate materials, such as multi-wall polycarbonate plates. These will behave in principle just like the combination of aluminium plate and polystyrene backing behind.

\section{Hygroscopic back}

Historically, many backboards have been moisture absorbent materials such as wood and card. To simulate these materials, a piece of washed, dense cotton canvas (632 $\mathrm{g} / \mathrm{m}^{2}$ ) was stuck to the inside surface of the aluminium plate.

The RH cycle amplitude behind the painting canvas was now rather large (Fig. 11), but the RH cycle measured close to the cotton on the back plate was smaller than when the back plate was bare.

The process here is a more complicated version of that proposed for Fig. 7. In that construction, the painting canvas was the main provider of water vapour. When the back plate also is hygroscopic it will compete for influence over the humidity within the enclosure.

As the temperature descends to a minimum, the $\mathrm{RH}$ at the back plate will tend to rise, but the back plate is hygroscopic and will absorb water vapour to move its surface $\mathrm{RH}$ towards equilibrium with its moisture content. This is not always the case, but here the effect of $\mathrm{RH}$ is dominant. The surface air of reduced mixing ratio will migrate to the painting canvas, which is about three degrees warmer. The simplified explanation is that during the journey through the temperature gradient to a warmer surface its mixing ratio will not change, so its RH will decrease. At the painting canvas surface, vapour will be released into the unexpectedly dry air, in an attempt to keep the surface $\mathrm{RH}$ in equilibrium with the painting canvas moisture content. Its moisture content will therefore decrease.

The two hygroscopic surfaces were competing as humidity buffers, which is why the observed $\mathrm{RH}$ change at the back plate was less than it was in the absence of the buffer surface. The painting canvas RH span was however of greater amplitude than when there was no buffer at the back.

The mixing ratios at canvas and back plate were changing in the same direction but were not identical, indicating that the air mixing is not entirely effective in ensuring a homogenous atmosphere at this rapid temperature cycle and with energetic exchange of water molecules between air and materials. Nevertheless, the mixing ratios were moving in phase, though the $\mathrm{RH}$ values at the two hygroscopic surfaces were in opposite phase.

This graph is an example of an important and widespread phenomenon-the destabilisation of the $\mathrm{RH}$ around an artefact when its buffer 'protector' is transiently at a different temperature. Thus, it can be a risky decision to put a water absorbent back plate on a painting. 


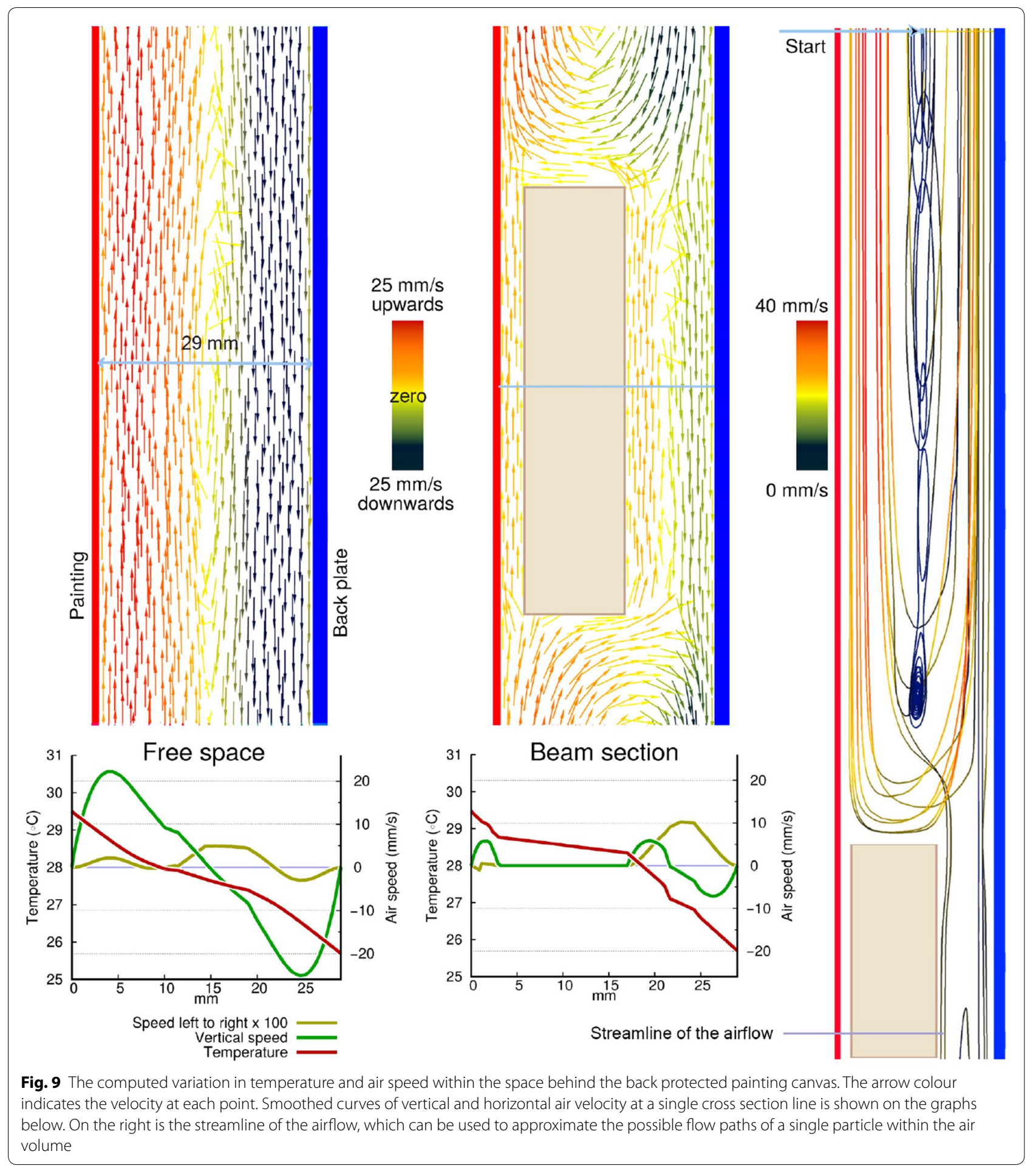




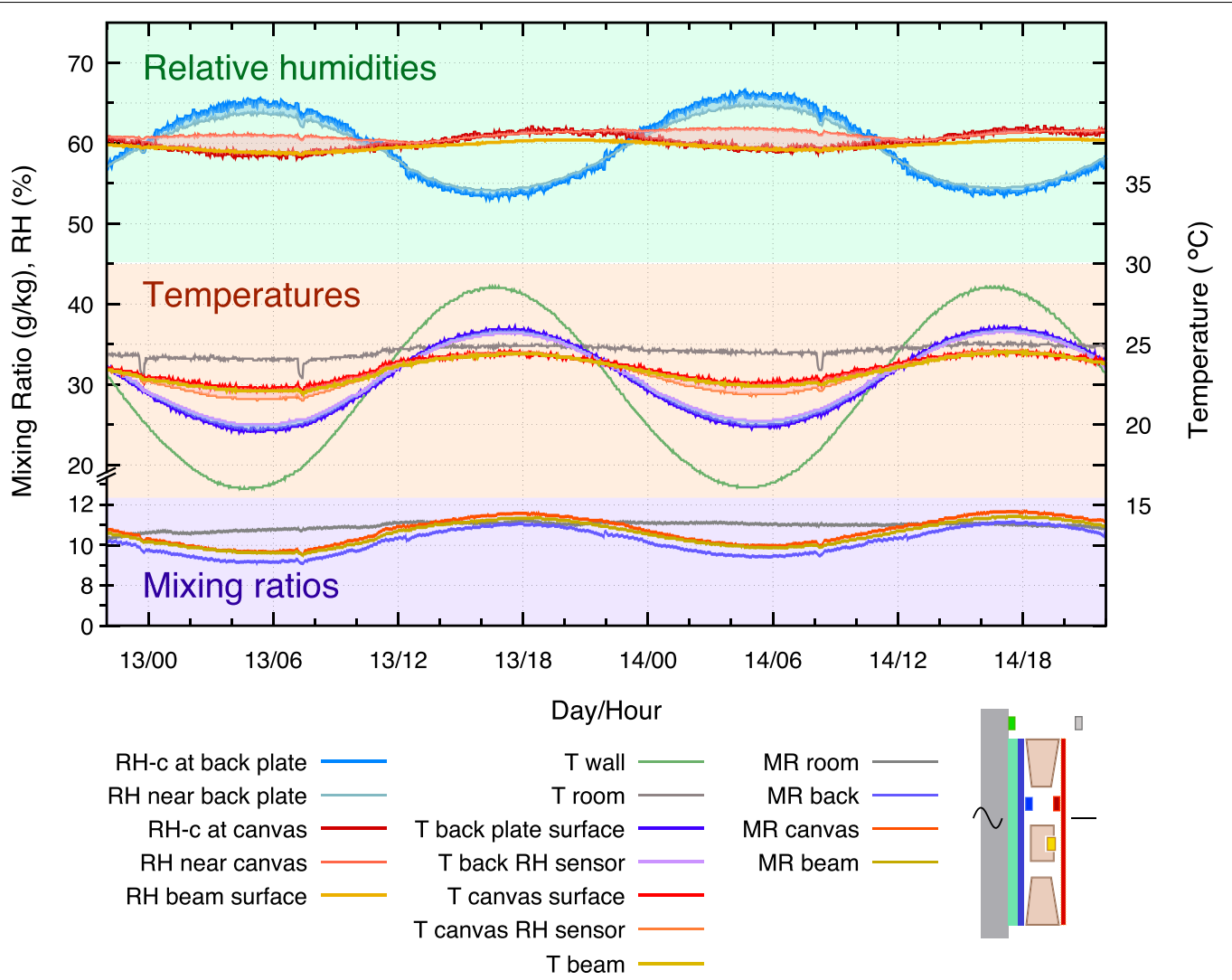

Fig. 10 The back plate was separated from the wall by a $20 \mathrm{~mm}$ slab of expanded polystyrene. $24 \mathrm{~h}$ cycle

\section{Buffering against air leakage}

There is much discussion among conservators about using hygroscopic back protection. Concern over leakage into the painting enclosure of a hostile room $\mathrm{RH}$ has dominated the discussion [9, 14]. However, humidity buffers play two distinct, separate roles: they serve to maintain a constant $\mathrm{RH}$ during temperature change, as shown by the temperature insensitivity of the cellulose isotherms, and they replace vapour leaking between the enclosure and the room air, even when there is no temperature fluctuation at all. This is because of the huge quantity of exchangeable water in the buffer compared with the tiny amount of water in the small air space. Thomson [10] and many subsequent authors have described how to buffer against leakage, with calculations to predict how much buffer is needed to give a desired time delay for the move towards equilibrium with the room climate.

If water vapour exchange with the room is an important consideration, due to a persistently unsuitable environment, one can add extra humidity buffer, so long as it is always at the same temperature as the painting. If the buffer material is close to the painting it is more likely to have close to the same temperature as the painting. If it is mounted on the back plate as it is sometimes done, it is more likely to have a temperature closer to that of the wall.

Putting an extra humidity buffer close to the canvas, and thus at a similar temperature, will not cause competition between the absorbent surfaces and it will slow down the $\mathrm{RH}$ change caused by leakage. For this to succeed, there must be thermal insulation to shield the buffer from the back plate temperature.

In order to show this, the same canvas that was used as the back buffer was instead fastened to the front of a 20 $\mathrm{mm}$ thick slab of expanded polystyrene insulation which fitted between the back plate and the painting canvas. It was spaced $3 \mathrm{~mm}$ behind the painting canvas to avoid spoiling the taut contours of the painting. The twenty four hour cycle is shown in Fig. 12.

The RH stability of the painting canvas was now very good, as was the RH between canvas and cross beam.

This combination of sealed back, impermeable insulation and a buffer layer close in temperature to the 


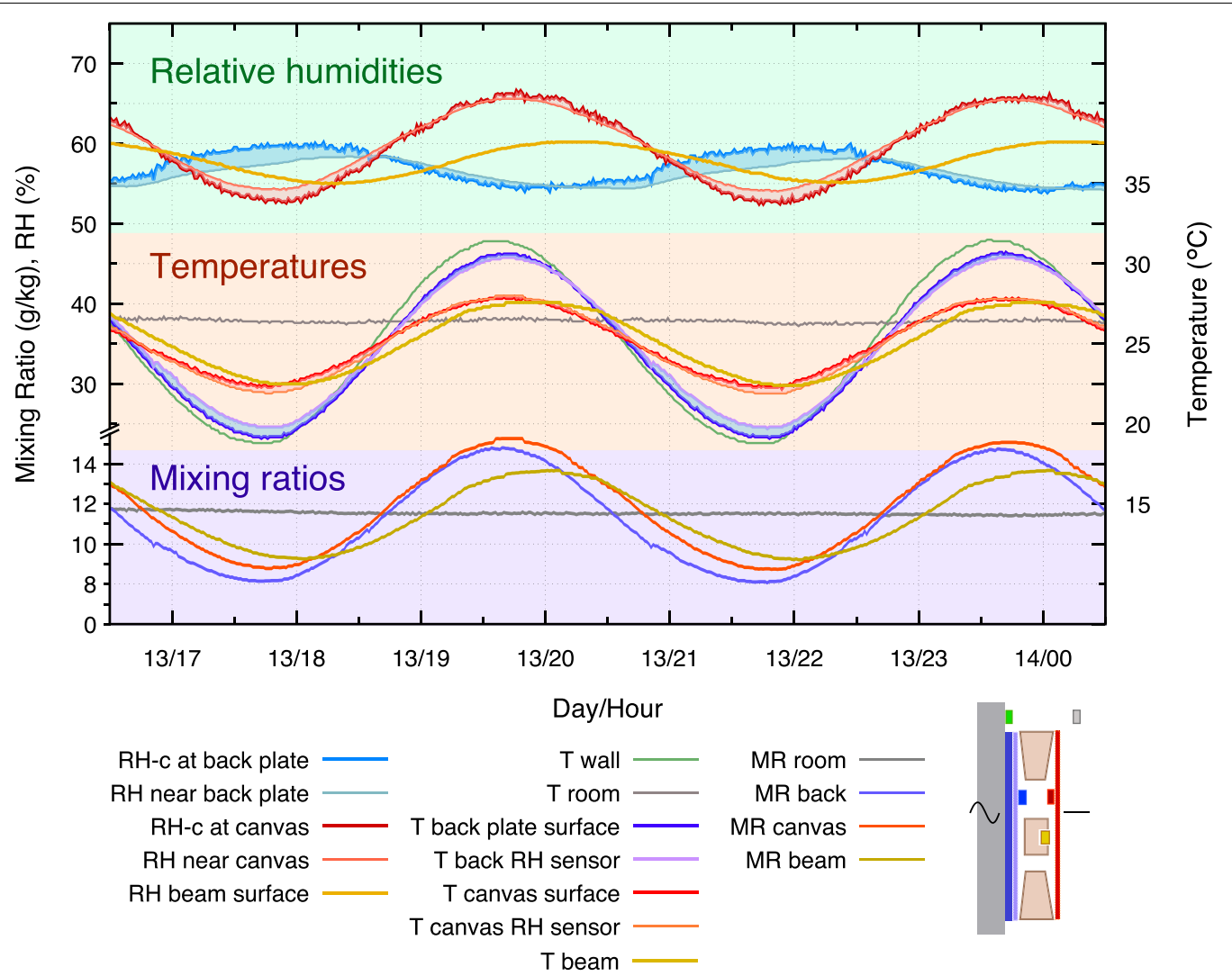

Fig. 11 Buffering by canvas stuck to the inside surface of the back plate, which was set against the wall. 4 hour cycle

painting canvas, gave stability to both temperature and relative humidity at the back surface of the painting, as well as providing a water reserve to compensate for leakage of room air into the enclosure.

The disadvantage of this arrangement is a large temperature difference between buffer and back plate and a correspondingly high risk of condensation on the inside surface of the back plate.

The mixing ratio in the narrow unbuffered void between the insulation and the back plate was varying in the same way as in the buffered space behind the painting canvas. This shows good air mixing throughout the space, even with reasonably close fitting insulation panels within the frame.

In winter, the wall may always be cooler than the room temperature and sometimes below the dew point of the air just behind the painting. In instances of very large $\mathrm{T}$ gradients and very slow air exchange rates, water can condense onto the back plate from vapour provided by the buffer at the warmer room temperature. However we consider this situation to be rare. Thus, it follows that insulation is not a universal good, just as buffer materials have to be positioned with understanding of the microclimatic implications of their presence.

This construction is best reserved for paintings with a relatively benign wall temperature but a seasonally variable room $\mathrm{RH}$, where extra buffering will defend against $\mathrm{RH}$ change caused by air exchange through the painting, or around its frame.

Condensation behind paintings has often been observed on the wall behind paintings both with and without back boards. The painting provides enough thermal insulation to keep the wall behind it cooler than the wall directly exposed to the room air.

Conservators, aware of the risk of condensation on the cool inner surface of the back board, have tried to avert it by seemingly intuitive solutions, such as cutting the corners of the back board, or by drilling holes through it. This won't help if the room air has a dew point above the back plate temperature.

\section{The effect of glazing the painting}

Nowadays many paintings have glass in front. This extra insulation layer will result in a greater temperature 


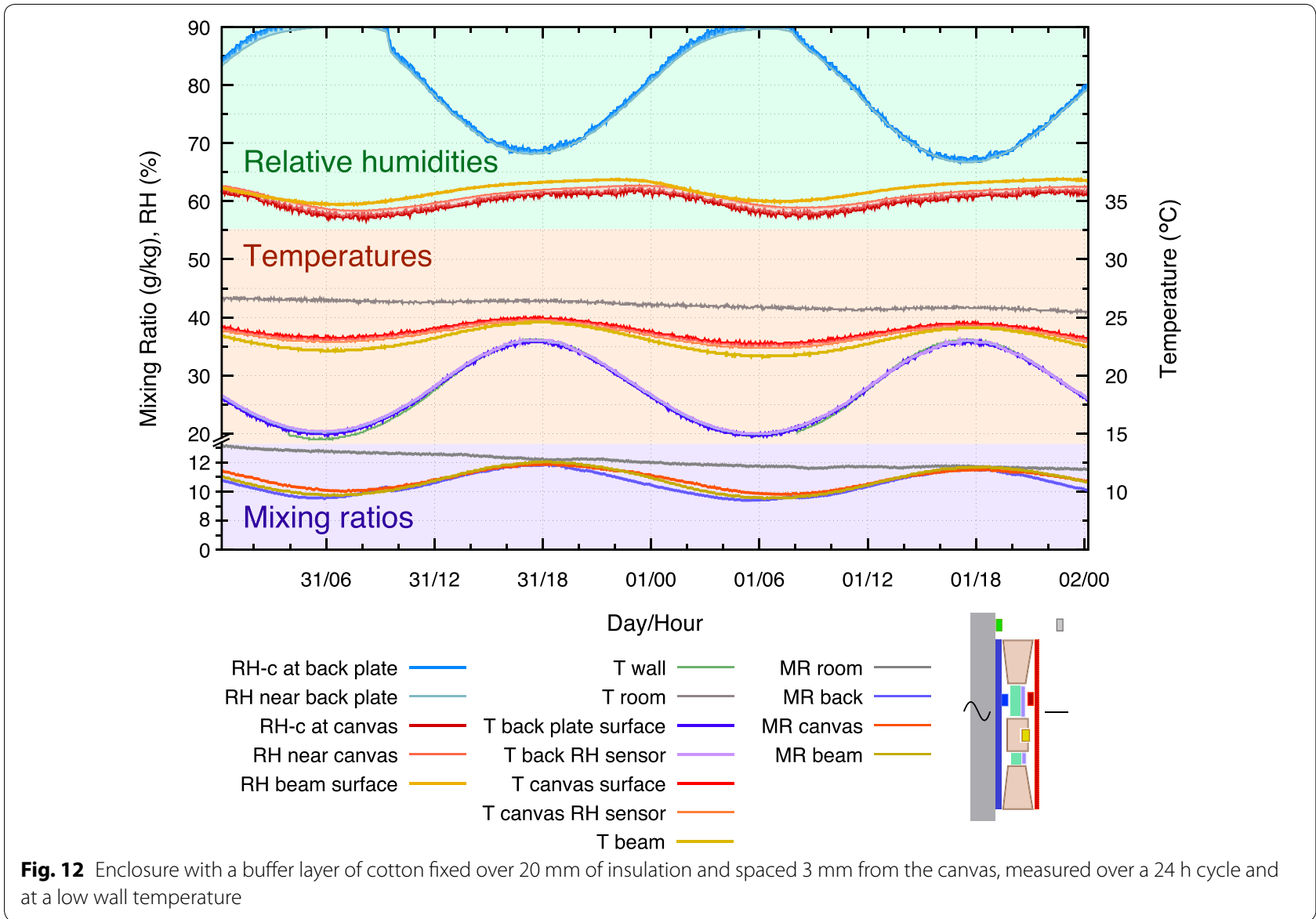

variation at the painting canvas as the wall temperature varies, but a smaller temperature difference between front and back of the enclosure. This results in a smaller RH cycle amplitude at the back plate and thus a diminished risk of condensation, however, glazing reduces temperature variation at the painting when the room air temperature changes rapidly. Figure 13 can be compared with the unglazed equivalent, Fig. 12.

The glass reduced leakage of air through the paint surface, so this construction is well suited to paintings which hang in a room with unsuitable $\mathrm{RH}$.

\section{When the wall has a more stable temperature than the room}

Outer walls in massive buildings as well as internal walls may have a more stable temperature at its inner surface than the air in the room. This situation was mimicked in Fig. 14. The painting was exposed, without internal buffer and without glass, to a varying room temperature while set against a constant temperature at its back plate.

There are several puzzling aspects of this diagram. The canvas and the beam $\mathrm{RH}$ were nearly in phase with each other but displaced from the temperature and the back plate $\mathrm{RH}$ phase. Yet the mixing ratio was uniform throughout the space and in phase with the temperature.

As the canvas temperature fell, it absorbed water vapour, as shown by the falling MR, but not enough to stem the rise in $\mathrm{RH}$ at its surface caused by the temperature reduction, which was now larger than when the wall was varying in temperature. As the fall in temperature diminished and then reversed, the canvas continued to absorb vapour, because its water content was out of equilibrium with its surface RH. After a half cycle, the temperature rose above ambient and the canvas quickly began to desorb vapour, which pushed its equilibrium surface RH down during the whole of the above ambient part of the temperature cycle. The result was a non-sinusoidal RH cycle about a quarter cycle in advance of the temperature cycle and the MR cycle.

Adding glass in front of the painting gives a similar pattern but with reduced amplitude of the temperature cycle.

The next experiment re-instated the internal insulation and buffer layer close to the canvas. 


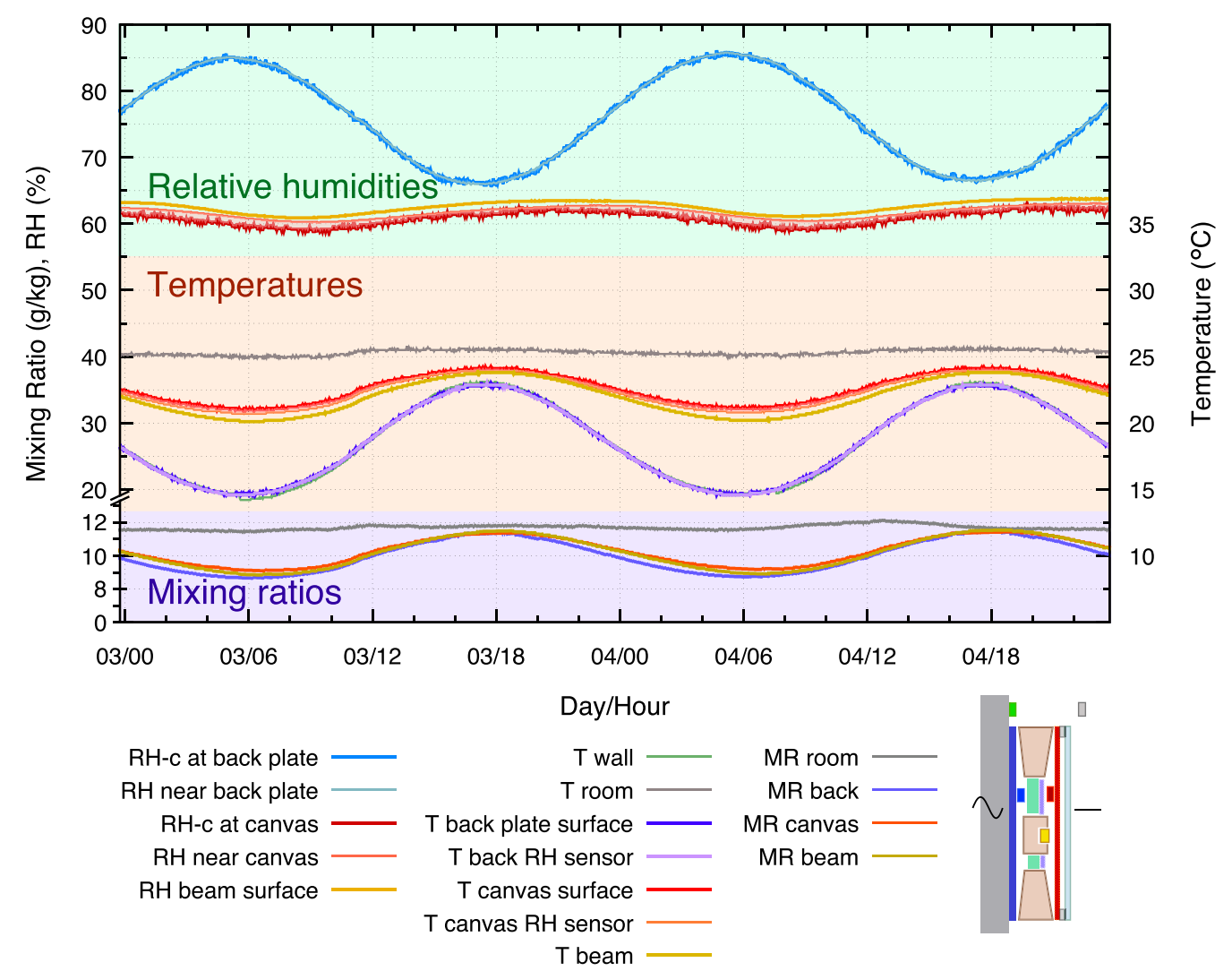

Fig. 13 Enclosure with a buffer layer of cotton fixed over $20 \mathrm{~mm}$ of insulation and spaced $3 \mathrm{~mm}$ behind the painting canvas. This is the same construction and wall temperature cycle as in Fig. 12 but with added glass, $3 \mathrm{~mm}$ thick, spaced $6 \mathrm{~mm}$ in front of the painting. The temperature cycle amplitude at the canvas was increased, and its average temperature was decreased, which reduced the RH variation at the back plate

Figure 15 shows the relatively unsteady $\mathrm{RH}$ at the canvas when it had the same back protection of buffer and insulation as in Fig. 13 but was instead exposed to a variable room temperature and a constant wall temperature.

In this construction, the moisture reaction of the combined canvas layers dominated the entire space, so the $\mathrm{RH}$ at the back was variable, even though its temperature was nearly constant. The fluctuation of $\mathrm{RH}$ at the painting canvas was lower but displaced by a quarter of a cycle.

\section{The effect of the wood components}

Many observers have commented on the better state of preservation of oil paintings on canvas in areas which are backed, at a millimetre or two spacing, by the wooden frame on which the canvas is stretched $[1,11$, 12] (Fig. 16).

All the graphs showed a reduced RH cycle amplitude in the $3 \mathrm{~mm}$ space between the wooden cross beam and the canvas. The cross beam was mounted horizontally, so convecting air currents would flush this space.
Nevertheless, the $24 \mathrm{~h}$ cycles showed a significant calming of the $\mathrm{RH}$ in this region.

The temperature gradient disturbance caused by the beam was quite small. Ligterink and Di Pietro [1] attributed the stretcher effect to the thermal insulation afforded by the wood, which reduces the RH fluctuation through moderating the temperature, without a significant contribution from sorption processes. They applied the temperature gradient as a single step change, followed by a steady state temperature difference.

Our cyclic experiments are closer to the real situation and reveal, in Fig. 6, that for the unprotected painting, the temperature was not much different between the beam-protected area and the exposed canvas, while the $\mathrm{RH}$ variation at the beam surface was much less than at the exposed canvas. The mixing ratio revealed moisture exchange with wood and canvas. This combination of buffering by both wood and canvas, together with constriction of air movement in the narrow space, as 


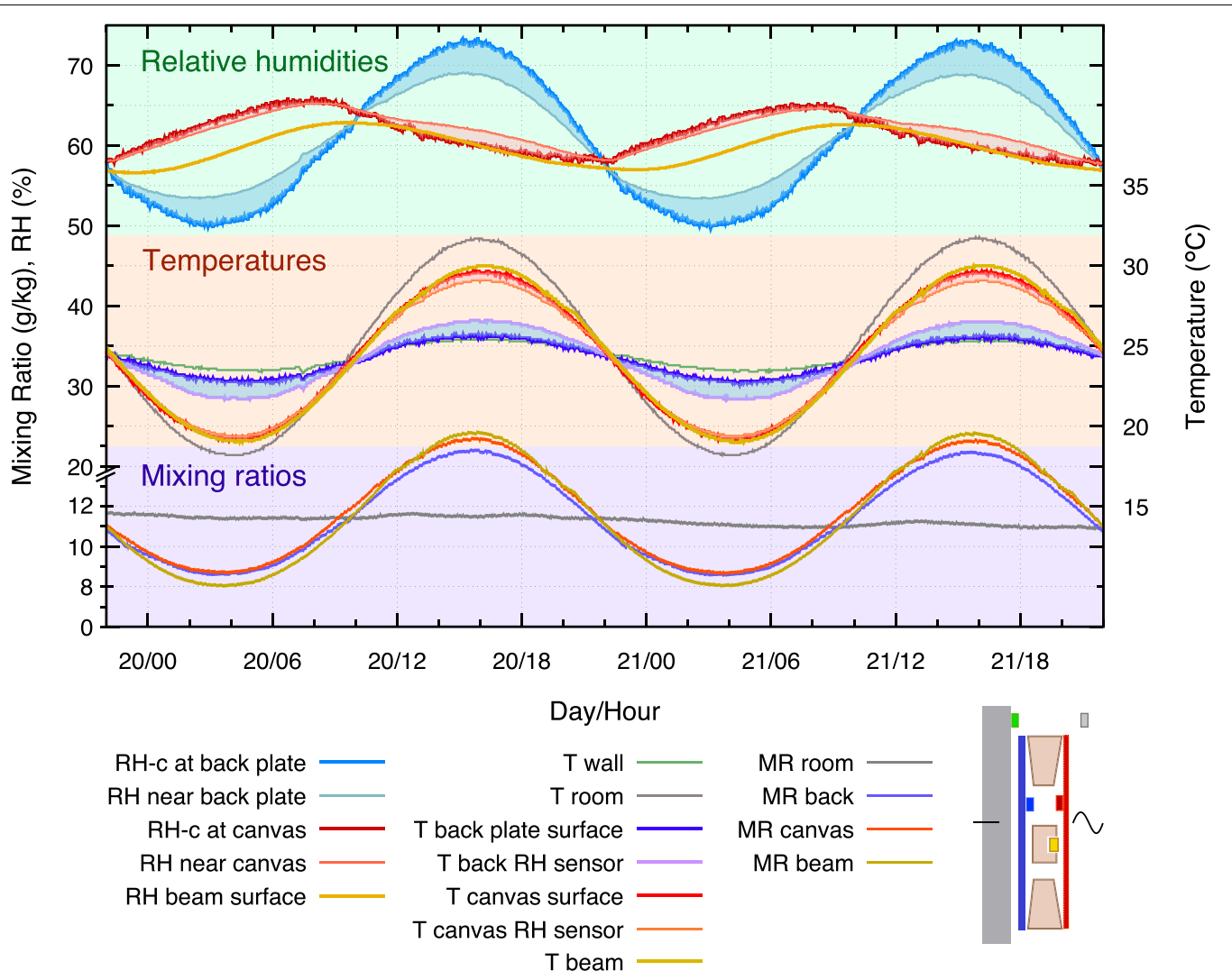

Fig. 14 The empty enclosure, exposed to a varying room temperature and a nearly constant wall temperature. $24 \mathrm{~h}$ cycle

shown by the diverging mixing ratio curves, seems an entirely adequate explanation for the better preservation of canvas paintings over the frame beneath.

The throttling of the air movement in the $3 \mathrm{~mm}$ gap between canvas and cross beam is shown in Fig. 9.

\section{Effect of air leakage}

We strove for airtightness to simplify interpretation of the experiments. However, we did not actually achieve better than 0.4 air changes per hour. Air exchange will tend to force the mixing ratio behind the painting towards that in the room. Nevertheless, we noticed no tendency for the mixing ratio within the enclosure to drift towards ambient. In a buffered space with a large reservoir of sorbed water in materials, this process can take a long time compared with the air exchange rate as measured by trace gases that do not interact with the materials.

In the insulated and buffered assembly there is a rather small volume of air compared with the perimeter seal length, so the air exchange rate is quite large. However, the small air volume has a small vapour content, so the buffer materials, the canvas and the wood, can cope with many air changes before there is a noticeable movement in the average mixing ratio of this volume towards that of the enclosing room.

On the positive side, the relatively rapid, yet safe, air exchange rate prevents the accumulation of damaging vapours emitted by the components of the enclosure: painted canvas, wood and insulation. If this remains a concern to the conservator, an active carbon loaded cloth can be sneaked into the space. If the painting is likely to be against a wall which is normally cooler than the room, the carbon absorber is best placed close to the back plate, because cool carbon absorbs better. The cloth that supports the carbon must be non water absorbent in this position.

\section{The larger environment}

The microclimate of the exhibition room should be taken into consideration. A wall which is frequently so cold that its surface temperature is sometimes below the dew point of the inside air requires special consideration. A painting hanging against such a cold wall, or even spaced away 


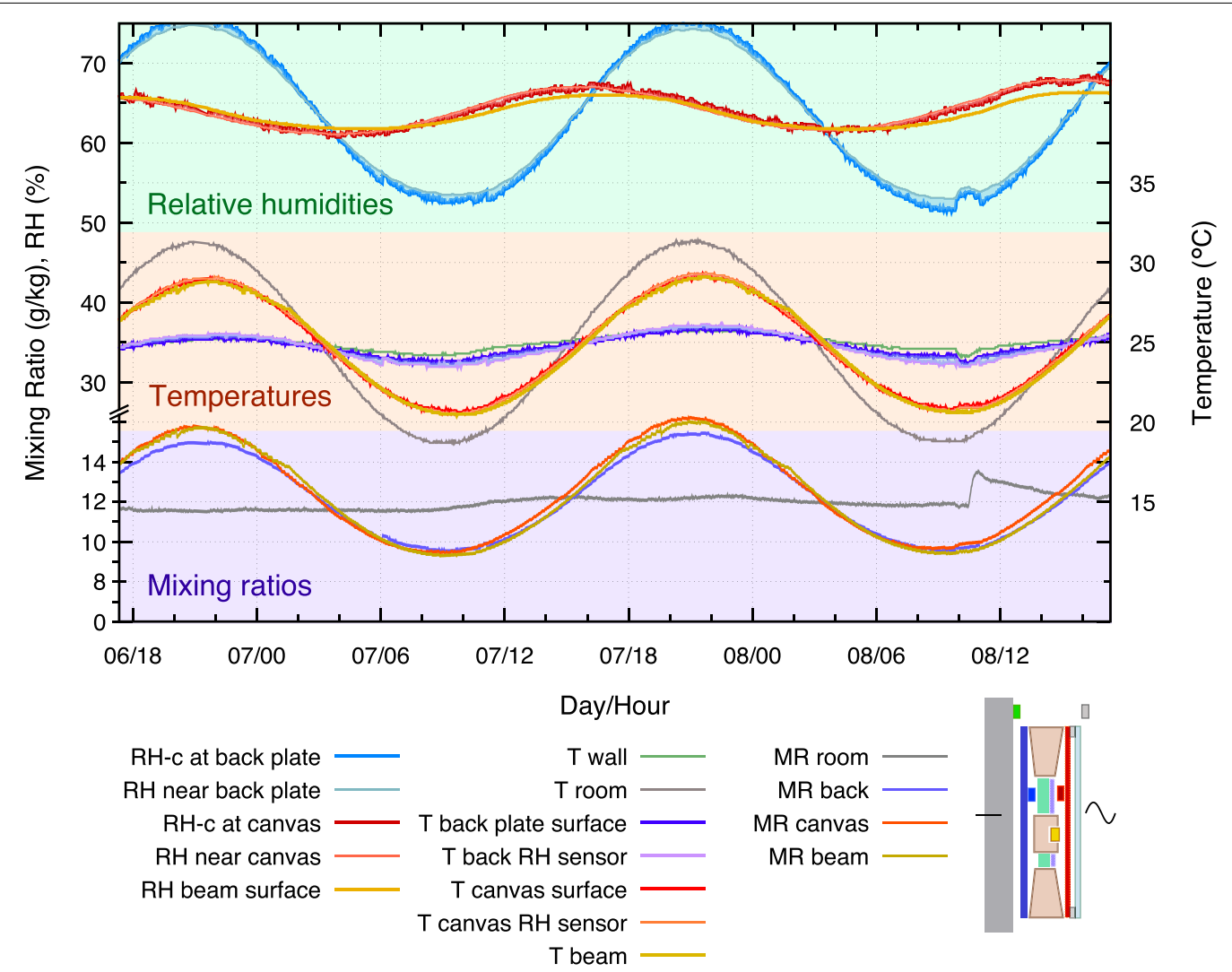

Fig. 15 Enclosure with a buffer layer of cotton fixed over $20 \mathrm{~mm}$ of insulation and spaced $3 \mathrm{~mm}$ from the canvas, which is covered by glass at 6 $\mathrm{mm}$ separation. The glass was exposed to a temperature cycle with the back plate held at a nearly constant temperature

from the wall, will inhibit the wall warming from contact with the room air. There is then a risk of condensation behind the painting.

Some outer walls provide a more stable climate behind the painting than the room provides to the painted surface [13]. The site of the painting should be studied before making an elaborate construction behind the painting. It may be that glazing the front of the painting will be a more effective preservative than a backing plate.

Another relevant consideration, which is not treated here, is the effect of sudden heating by sunlight, or by spot lights, which can cause moisture movement from the painting canvas to the interior of the void behind it. This was described by Padfield et al. [2].

Light energy absorbed by different colours will cause horizontal movement of water vapour behind the painting. A one degree difference in temperature corresponds to a 3\% difference in $\mathrm{RH}$ in the space immediately behind the painting at that point.

\section{Discussion}

Figure 17 summarises the performance of the enclosure when it was exposed to a cyclic temperature change.
Table 2 provides an overviw of the variables in each setup. It shows the span of the $\mathrm{RH}$ and temperature changes for each enclosure structure, normalised to the wall temperature span. There are slightly different temperature ranges for each experiment, which may cause minor differences in the reported results.

The merit of each construction is judged by how small a RH span arises at the back surface of the painting canvas. In several constructions, there is a large span in $\mathrm{RH}$ close to the back plate. This can cause damage within the assembly, but not directly to the painting. A small temperature span at the painting is also good, but temperature is not as strong a cause of dimensional change as the $\mathrm{RH}$ span, under the same environmental cycle.

The diagram shows clearly the main features of the various treatments. The unprotected painting showed the largest variation of $\mathrm{RH}$, entirely caused by its temperature divergence from the room temperature.

Backing the frame with a moisture inert and impermeable metal sheet greatly stabilised the canvas $\mathrm{RH}$ but caused a large RH fluctuation at the surface of the back plate. This could cause condensation if the wall becomes sufficiently cold. 


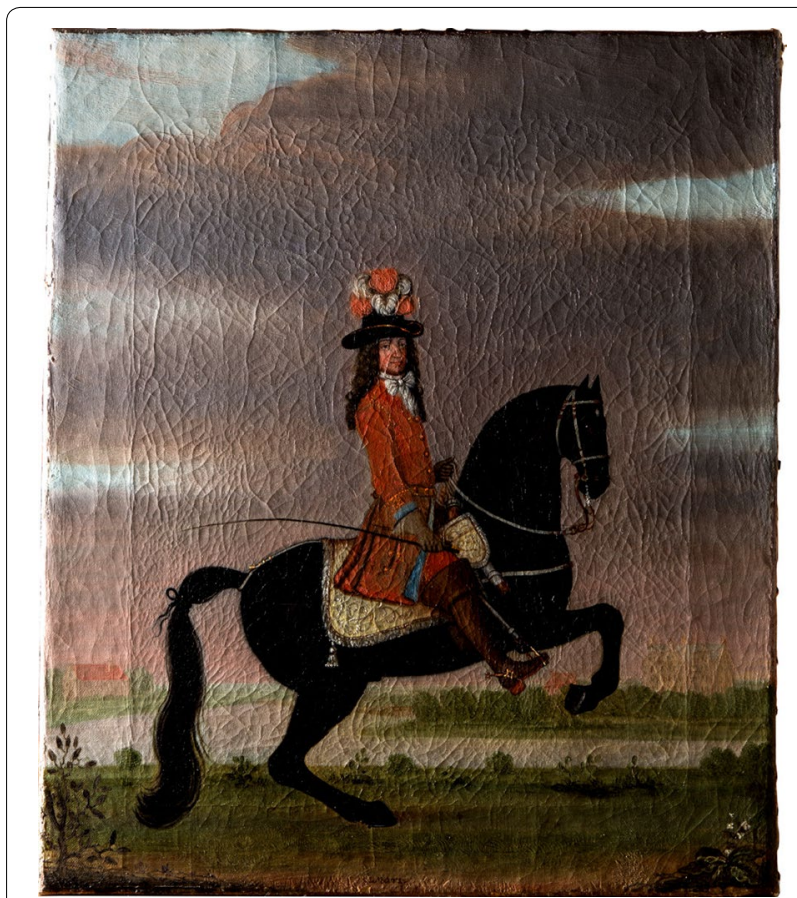

Fig. 16 An anonymous painting from around 1690, illuminated by raking light to show the protective effect of the wooden frame behind the canvas. $390 \times 460 \mathrm{~mm}$. From the Rosenborg Palace collection, Copenhagen. Photo by Berit Møller

Insulating between the wall and the back plate gave good stability to the painting canvas and much reduced the risk of condensation on the back plate, while transferring the condensation risk to the wall behind the insulation.

Adding buffer capacity to the back plate, in the form of a layer of cotton canvas, reduced the condensation risk there but increased the $\mathrm{RH}$ variation at the painting canvas.

Bringing the buffer close to the painting canvas, with insulation behind it, would better stabilise the painting canvas RH against leakage, but exposed the back plate to a very high $\mathrm{RH}$ fluctuation with correspondingly high condensation risk.

Adding glass in front of the painting slightly increased the temperature span at the painting canvas, gave a reduced span at the back plate and reduced the $\mathrm{RH}$ variation there.

The two last clusters on Fig. 17 show the microclimate when the room temperature was more variable than the wall temperature. The temperature and RH spans were increased for the painting canvas and the wooden beam but the back plate had a moderate RH span, increased when there is internal insulation and buffering.

\section{Conclusions}

Our conclusion is that the best back protection for the painting amongst the examined experimental set-ups was an impermeable, non-hygroscopic plate, with spacers to separate it from the wall. This is the second cluster from the left in Fig. 17. For future work, it would be worthwhile looking at the much used polycarbonate, as it is transparent and lighter.

Hygroscopic back boards can infer a risk of unstable climate behind the painting because even a small fluctuation in temperature difference between back board and painting canvas can cause a large $\mathrm{RH}$ swing at the canvas. The Canadian Conservation Institute [14] recommends hygroscopic backs. This advice is good for situations where the temperature is uniform but the room $\mathrm{RH}$ is seasonally low, or high. It is therefore important to consider the geographical setting of the painting, as well as the room conditions in front of it.

The current authoritative advice on back protection of paintings fails to warn about the high $\mathrm{RH}$ which can arise at the back plate when there is a transient low temperature arising from the outside weather.

There is no reason to ventilate the space behind the painting. The space is unlikely to have an air exchange rate lower than once per day, because of the large perimeter seal compared with the enclosed volume. The often expressed fear of mould growth in the sealed space is justified, because of the high RH at the back board when it is cooler than the painting. However, ventilation with room air through perforations will not help, because it introduces air, often humidified in museum galleries, of a moisture content which may well have a dew point close to the backboard temperature.

There is a widespread view that humidity buffers are always beneficial, but this is wrong wherever there is a temperature difference between the protective buffer and the object in its care. The climatic situation must be analysed. Only in modern purpose-built museums is temperature uniformity likely. In historic houses and churches, the microclimate must be measured and studied to confirm the safety of adding a humidity buffer behind a painting. Many outbreaks of mould growth on art can be directly attributed to a low temperature at its surface, combined with a moderate $\mathrm{RH}$ in the warmer adjacent air.

We have concentrated our attention on moderating $\mathrm{RH}$ change directly behind the painting canvas, but temperature variation is also important to the stability of the painting. Fortunately, the constructions which perform best to moderate $\mathrm{RH}$ also perform well on temperature stability. 

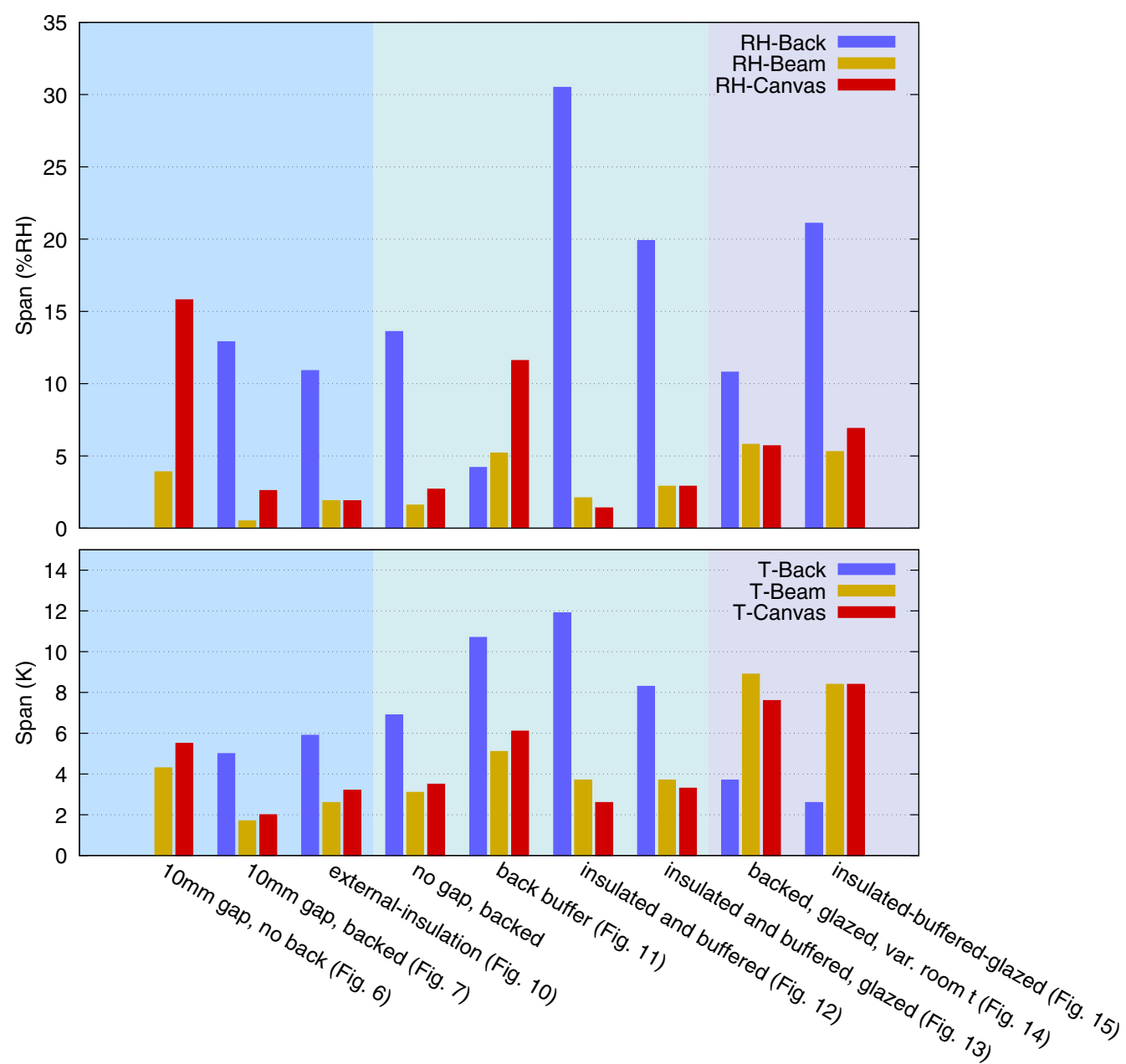

Fig. 17 A synoptic view of the variability of the temperature and $\mathrm{RH}$ at three places in the painting enclosure. The $\mathrm{RH}$ variation is the measured variation at sensors adjacent to the backboard, near the painting canvas and at the painting side of the wooden beam. The rightmost two sets of columns represent a steady wall temperature with varying room temperature. All assemblies include an aluminium back plate except for the first (Fig. 6)

Table 2 Overview

\begin{tabular}{|c|c|c|c|c|c|c|c|c|}
\hline & $\begin{array}{l}\text { Aluminium } \\
\text { back board }\end{array}$ & No gap & $10 \mathrm{~mm}$ gap & $\begin{array}{l}\text { External } \\
\text { insulation }\end{array}$ & $\begin{array}{l}\text { Internal back } \\
\text { buffer (canvas) }\end{array}$ & $\begin{array}{l}\text { Internal insulated } \\
\text { cotton buffer }\end{array}$ & Glazed & Varied room $\mathrm{T}$ \\
\hline Figure 6 & & & $x$ & & & & & \\
\hline Figure 7 & $x$ & & $x$ & & & & & \\
\hline Figure 10 & $x$ & & & $x$ & & & & \\
\hline (No gap) & $x$ & $x$ & & & & & & \\
\hline Figure 11 & $x$ & $x$ & & & $x$ & & & \\
\hline Figure 12 & $x$ & $x$ & & & & $x$ & & \\
\hline Figure 13 & $x$ & $x$ & & & & $x$ & $x$ & \\
\hline Figure 14 & $x$ & $x$ & & & & & & $x$ \\
\hline Figure 15 & $x$ & $x$ & & & & $x$ & $x$ & $x$ \\
\hline
\end{tabular}


These results are based on specific parameters and materials with known sorption properties. The possibility of differences in materials' sorption as a result of materials chosen and their degradation implies a need for further understanding of the interaction with the climate behind the painting. In the future further experimentation could enhance our understanding of the challenge with back protection of paintings.

\section{Abbreviations}

CFD: computational fluid dynamic; MR: mixing ratio; RH: relative humidity.

\section{Acknowledgements}

These experiments were performed at the School of Conservation of the Royal Danish Academy of Fine Arts. The experimental apparatus was constructed at the Fablab at Roskilde University, Denmark.

Special thanks to Poul Klenz Larsen for invaluable input and advice.

Henning Matthiesen helped with the air exchange measurement. Useful comments were sent by Thomas Biney, David Bugeja, Dario Camuffo, Sarah Staniforth, Frank Ligterink, Giovanna Di Pietro, Jørgen Wadum, David Thickett and Stephen Hackney.

Figure 16 is published by permission from the Danish Royal Collection.

\section{Authors' contributions}

TP: Main author, experiment design, programming and data reduction. NP: Building the apparatus. DL: Air movement simulation. AT: Construction of the painting, preliminary experiments. AN: Running the experiment day to day CA: Managing, experimental work and editing. MS: Experimental work and editing. All authors read and approved the final manuscript.

\section{Funding}

The Royal Danish Academy of Fine Arts, Schools of Architecture, Design and Conservation has supported this research.

\section{Availability of data and materials}

The dataset is available at https://www.conservationphysics.org/backboard/ The materials are described in experimental sections.

\section{Competing interests}

The authors declare that they have no competing interests.

\section{Author details}

${ }^{1}$ Conservation Physics, Roskilde, Denmark. ${ }^{2}$ Fablab RUC, Roskilde University, Universitetsvej 1, 4000 Roskilde, Denmark. ${ }^{3}$ The Royal Danish Academy of Fine Arts, Schools of Architecture Design and Conservation, Phillip de Langes Allé 10, Copenhagen K, Denmark. ${ }^{4}$ AT Konservering, Hollænderdybet 32, 2300 Copenhagen, Denmark.

Received: 13 February 2020 Accepted: 2 September 2020

Published online: 01 October 2020

\section{References}

1. Ligterink FJ, Di Pietro G. Canvas Paintings on Cold Walls : Relative Humidity Differences Near the Stretcher. In: Padfield T, Borchersen K, editors. Museum Microclimates. National Museum of Denmark; 2007. https:// www.conservationphysics.org/mm/ligterink/ligterink.pdf.
2. Padfield T, Berg H, Dahlstrøm N Rischel AG. How to Protect Glazed Pictures from Climatic Insult. In: Roy V, editor. Proceedings of the Rio de Janiero Conference of the International Council of Museums - Committee for Conservation. London: James \& James (Science Publishers), 2002;1:80-85. https://www.conservationphysics.org/framepic/glazedpics.pdf.

3. Padfield T, Padfield N. A Workshop Cool Plate. 2019. https://www.conse rvationphysics.org/coolplate/coolplate01.html.

4. CEN standard 16242:2012 Conservation of cultural heritage - Procedures and instruments for measuring humidity in the air and moisture exchanges between air and cultural property.

5. Please refer to Tim Padfield's article on MR and AH: https://www.conse rvationphysics.org/teabag/ah_mr.html.

6. Gregers-Høegh C, Mortensen MN, Christensen ME, Andersen CK. Distorted oil paintings and wax-resin impregnation - a kinetic study of moisture sorption and tension in canvas. J Cult Heritage. 2019;40:43-8.

7. Sorbtion data. https://www.conservationphysics.org/backboard/coolp late-article-sorption-calculations.zip.

8. Urquhart AR, Williams AM. Absorption isotherm of cotton. J Textile Inst. 1924;2:559-72.

9. Michalski S. Risk analysis of backing boards for paintings: damp climates vs. cold climates. In: Minimo Intervento Conservativo Nel Restauro Dei Dipinti: Atti Del Convegno, Thiene (VI), 29-30 Ottobre 2004: Secondo Congresso Internazionale: Colore E Conservazione, Materiali E Metode Nel Restauro Delle Opere Policromi Mobili. CESMAR7: The Center for the Study of Materials for Restoration. Padua: II Prato, 2005. p. 21-27.

10. Thomson G. Stabilisation of RH in exhibition cases: hygrometric half time. Stud Conserv. 1977;22:85-102.

11. Michalski S. Paintings: their response to temperature, relative humidity, shock, and vibration. In: Mecklenburg FM, editor. Art in Transit: studies in the transport of paintings. Washington DC: National Gallery of Art; 1991. p. 223-48.

12. Vila A, Murray A, Andersen CK, Izzo FC, Fuster-López L, Aguado-Guardiola E, Jiménez-Garnica R, Scharff A. Picasso 1917: An insight into the effects of ground and canvas in the failure mechanisms in four Artworks. Conserv Modern Oil Paintings. 1917;2019:245-53.

13. Padfield Tim, Robinson A. The climate behind pictures mounted Against the outer walls of the Chapel of Ledreborg, Denmark. In: Preprints of the ICOM (International Council of Museums) Committee for Conservation, Edinburgh, 1996;1:72-75. https://www.conservationphysics.org/ldrbrg/ Idrbrg.pdf.

14. Hartin DD. Backing Boards for Paintings on Canvas - Canadian Conservation Institute (CCI) Notes 2016;10/10. https://www.canada.ca/en/conse rvation-institute/services/conservation-preservation-publications/canad ian-conservation-institute-notes/backing-boards-paintings.html.

\section{Publisher's Note}

Springer Nature remains neutral with regard to jurisdictional claims in published maps and institutional affiliations.

\section{Submit your manuscript to a SpringerOpen ${ }^{\circ}$ journal and benefit from:}

- Convenient online submission

- Rigorous peer review

- Open access: articles freely available online

- High visibility within the field

- Retaining the copyright to your article

Submit your next manuscript at $\boldsymbol{\nabla}$ springeropen.com 